\title{
Surveillance and techniques of disciplinary selfhood: Notes towards the transmission of anthropological knowledge.
}

\section{Ian Harper}

\section{$\underline{\text { Introduction }}$}

In the last two years, during which time I was simultaneously writing up my thesis, I have taught at three different universities. Having not worked as a Teaching Assistant, I launched immediately into being responsible for both the development of course content, lecturing and the running of seminars. During the development of the paper, it was suggested that I might wish to share some of the experiences - before they get lost - of this move to teaching. In this experientially driven (and not particularly theoretically informed) narrative, then, I share my sense of how, and under what conditions, I developed both the contents for the courses for which I was responsible, as well as some of the teaching styles I used. I also sketch some of the forces - not all of which I am fully conscious of - that have assisted in molding these forms of knowledge to be institutionally transmitted to students of the discipline.

\section{$\underline{\text { SOAS }}$}

My first experience in anthropological teaching / self-learning and an important reference point of departure for future teaching was at SOAS, during the MPhil year prior to fieldwork. With a core of about twelve of us, ranging from those just starting out on their research careers to those who had finished writing up and had embarked on teaching, we called ourselves E@TM. This forum was started as an attempt to counter a sense that previous researchers had of SOAS Ph.D. student isolation. Jennifer Law and David Mills, then two mature postgraduate students, put together a funding proposal to the National Network for Teaching and Learning Anthropology (NNTLA, funded by HEFCE) and were awarded a grant. With this external funding a space was created, and institutionalized on a weekly basis with a room, where we had defined what it was we wanted to learn about and had then run sessions ourselves - inviting faculty or external speakers as, and when, we felt they were needed. By starting with introductory brainstorming sessions we sketched out what we might look at, and develop.

We ended up exploring the following, each facilitated by individuals within the class, and using a range of techniques. Sessions included those on virtual ethnography and practical Net-familiarization sessions; Urban Anthropology; A discussion session on the limits and problems of SOAS Research Training, with possible solutions; Video/Ethnography Workshop and rethinking the methods and ethics of Visual Anthropological Research; Power and Development 1: Perceptions of Power in SOAS Anthropology Department, as a video recorded PRA exercise; Power and Development 2: Social movements first, ethnographic research second?; What is anthropology for - Group Debate/Discussion; Multi-sited Ethnography - Reading George Marcus; Non-WASPish Anthropology and the SOAS take; Spot the Genre of anthropological writing!; Making PhD supervisions

work for you - a discussion of the personal and institutional dynamics; A one day creative 
writing workshop; Desert Island Texts - Individual 'sound-bite' presentations of texts that inspire; Interview as dialogue or inquisition? (Video recorded): Visuality and Anthropology - Presentation of the work of three filmmakers, and debate; Evaluating Evaluation: Thinking through Assessment. (video recorded); Turning to the Future Discussion of the limitations and possibilities of SOAS research training. We finished with an open collective letter composed by seminar attendees regarding the future of MPhil training course (for an attempted academic article on this year visit www.soas.ac.uk/EaTM/7.html).

Being actively involved in this enjoyable learning experience, with the space to experiment, make mistakes in a supportive and peer driven environment was particularly useful in providing the confidence to also teach in ways other than the lecture / reading presentation seminar format. I now actively draw on a number of these sessions and methods in the ways that I teach, for both masters and undergraduate students (although I have not, yet, had the courage to develop an open course based entirely around student needs!) ${ }^{1}$. I have actively drawn on these experiences in teaching at other institutions.

\section{$\underline{\mathrm{UCL}}$}

Here I taught a term on the course classic modern ethnographies and research methodologies to masters' students of medical anthropology. Asked to stand in at the last minute for a senior professor who went to Johns Hopkins for the term, I was given full rein to teach however and, within the outline, whatever I wished. From a list of more recent ethnographies I made, we chose five together and we read them critically on alternate weeks. We were able, to my surprise, to easily fill out two-hour long sessions. We simply started by teasing out what the reader liked about the text and how it was written, before moving more critically towards examining the relationship between theory, empirical evidence, and styles of writing.

The methods classes were run experientially, drawing on the SOAS experience. For example, I made a cup of tea and chatted with the class as they took "field notes"; reading these out to each other highlighted how many judgments are made in this observational process, how interpretation takes place from the moment of observations, and how as much is left out as written in etc. We then turned these into a more analytic piece, and reflected on styles of writing, and the incorporation of theory. For interviewing this was also done experientially - two people interviewing the same person, who then reflected on what they felt they could and could not say etc. The course was both enjoyed and useful, in the feedback received. I had no contact, other than a series of meetings with the professor whose course it was, with other faculty members.

\footnotetext{
${ }^{I}$ There were, however, those who were skeptical of this process and perceived the support we received from the department (never turned into money, for example) as a cop out by staff more interested in research than teaching. Self-motivated and self taught research students, require less "teaching", therefore releasing time from teaching for that all important research.
} 


\section{$\underline{\text { Brunel }}$}

From this I moved on to teach at Brunel on a part time contract, from money that a senior faculty member had to buy herself out of teaching while researching. Here I taught ethnographic methods to 1st and 2nd year human science undergraduates (up to 180 students each), developed six hours of lectures on the "body" as part of a second year undergraduate course, and co-developed and co-taught two modules for medical anthropology. Although there was a points system to protect exploitation, particularly of junior staff, part time staff did not have the "buffer" of points awarded for personal tutoring and some of the less arduous administrative duties. It was openly admitted to me that the part time staff, particularly those teaching for the first time, do not get the best benefits from the system. The nagging sense of resentment that I was left with, and a sense that despite the valuable experience and individual support and relations developed within the department, is one that I now realise is shared by many others, across departments, on these part time contracts early on in their careers; a question of the political economy of part time junior teaching contracts within higher education.

For the teaching itself, I had notes from the previous lecturers, good informal relations with a number of staff and was fortunate enough to be able to meet up with one who was on research leave, to discuss one of the courses. The core of the course for the first years was an experiential game, in which two groups enacted out a role-play as two different "cultures" and were then sent off to take notes, without talking, on the other group's behaviour. This formed the basis of the course, which had interspersed brief lectures and other experiential exercises. I had simultaneously prepared some lectures incase some of the sessions hopelessly failed (which, fortunately, they did not). Similarly, for the second year's I developed a range of exercises (interviewing, observational, discussions on ethical topics, video material, some lectures, brainstorming how we may undertake an ethnography of Brunel, looking at writing styles) to cover, broadly, the process of doing ethnography.

I was given total freedom to teach anything I liked on the "body", and I developed the lectures with considerable trepidation, drawing on my own readings and the course I had sat as a master's student at SOAS. The reading lists I used are soon to be available on the web (www.anthropologymatters.com). For the medical anthropology modules I had much more support. I was supported in the introductory course, by the attendance at my first three lectures by my co-lecturer, a senior professor who was supportive and encouraging. The course I worked on for anthropology and public health was particularly enjoyable, as it involved close cooperation with another member of staff in defining both content, and approach. Able to draw on my own research experience within an area I particularly enjoy, teaching this course was most fun. It was also the closest I have come to bringing teaching and research together, or rather drawing on field research to inform the teaching. Falling into the second term I had also overcome my fear of lecturing, and begun to appreciate its performative elements. The seminars, after discussion of a number of ways they could be run (and drawing on the SOAS model) I handed over entirely to the masters students, to run as they saw fit - the only stipulation was that the content had to be, even if only marginally, related to the content of the lecture. They experimented with debate, 
role-plays, their own presentations, presented their research ideas etc. I would meet with those who had decided what to do to support their ideas and give suggestions on methods when necessary. All involved in them particularly enjoyed these seminars. Interestingly, when I offered this method to the undergraduates they preferred the traditional format of presenting readings and discussion.

I found that my previous interest in participatory teaching was both enjoyed by the students, as well as welcomed by the staff in the department. Finally, the experience of lecturing while still writing up the Ph.D., although at times very stressful and hugely time consuming, seems (in retrospect at least) a partially valuable exercise. The old adage that you never learn something so well as when you have to teach it was very useful for writing the Ph.D. Certain chapters, as a consequence, were strengthened by closer readings of a number of theoretical positions that the teaching process forced upon me. This was further deepened by the stimulation of feedback and further learning that comes from a rigorous seminar engagement with a range of students.

\section{$\underline{\text { SOAS }}$}

At SOAS a number of changes are underway, and as a consequence morale in the department is currently at an all time low. Forced into a process of facultisation with little discussion (despite all the new managerialism speak of partnership and consultation), the loss of a departmental office and administrative support to the faculty level has resulted in administrative chaos. It is my impression that with severe debts, the facultisation process has been one in which change is associated with decreased funding (under a different name). It is likely that with the imminent retirement of a number of senior members of the faculty, they could be replaced by fewer junior staff on short-term contracts. At the same time the demands from above are that student numbers are to be increased.

Into this I arrived as a junior lecturer on a two-year contract. With the task of developing new courses, daunting enough as it is, there is also increasing insistence that I should attend courses on teaching and learning (so far resisted). These arrive in the form of email circulars advertising teaching courses and certification, and other courses - like understanding and working with dyslexic students - which while I recognize their importance, just feels overwhelming at a time of settling into a new post, and developing curricula. As we move to faculties, and I (as does everyone) grapple with understanding the new system, these are received not as support, but as a further burden to feeling already over worked. At the same time other forms of surveillance - like the all important publications outputs arrive as attachments - also need to be filled out.

Again I have been given broad scope to teach what I like, and develop course content to my strengths. While drawing on the previous course materials of those I am filling in for, from others in the department and lesson plans developed at Brunel (and this teaching experience in no small part contributed to me getting the job), I was also able to shift the contents to my own areas of research interest. 
$\underline{\text { Some deliberations on moving between departments }}$

Moving from one institution where I was taught the bulk of my anthropology, SOAS, to first UCL, then Brunel required a degree of adaptation to the differing cultures of the anthropology departments. Particularly, this involved learning what is acceptable as anthropology, outside the process of doing anthropological fieldwork, the ritual rite of passage of being there. To my surprise, the degree to which "postmodern" ideas and cultural studies theory - more mainstream in the anthropology I was taught at SOAS - are acceptable, vary. I was encouraged to teach that which interested me, but I realized there were limits. In casual conversations with other faculty members I frequently had to strongly defend my choices of reading materials. At times I felt I was in a continuous struggle with those patrolling the acceptable boundaries of anthropology, and in one departmental culture where the term "post modernist" or "cultural studies" was spat out from clenched teeth, as a form of insult. As the most junior lecturer I felt both obliged to reign in teaching certain theory (like Foucault for example). I found myself exercising a degree of self-surveillance in what I taught, part of the microphysics of power within the disciplinary normalizing process. I think that what surprised me, however, was that despite this tendency to conservatism on my part, how individualistic courses are, developed along the lines and interests of faculty members. I was surprised that there was not more of a departmental line on course content, as well as relieved, yet simultaneously feeling vulnerable that I could play the course to my strengths (which requires, lets face it, far less reading as preparation). In short, a peculiarly paradoxical emotional experience.

\section{As an object of research / surveillance}

The suggested anthropology benchmarks - as circulated to us prior to the conference seem to me to be broad and general enough to incorporate a range of individual approaches etc. and cover most of the important points, without appearing too prescriptive. Simultaneously, the QAA begins to take into more consideration students' feedback and that of employers - part of its commitment to democratization and commercialization of higher education. One question here is who, precisely, are the employers of anthropology graduates and postgraduates? One immediate thought is that if many are snapped up as part of the global development machinery, the demands and feedback may be incompatible with the type of student suggested by the internally defined benchmarks.

This aside, and that one of our responsibilities is in representing "other" parts of the world, why is it that there seems to be no reference in these documents to review and feedback from representatives of the countries about which we teach? Here I share two recent experiences. I recently presented as part of a panel at a public discussion forum in Nepal on "the current crisis, roles and responsibilities of social science researchers". As Nepal enters a period of tumultuous social and political upheaval, examples were given of the increasing irrelevance of social scientists in engaging in issues of current importance within the countries they work, and that the knowledge they produce is all too frequently put to the use of the elite in maintaining the status quo (one needs only think 
of how much of the anthropology of Nepal focuses on the idea of "tribals" and their own internal logic and how that knowledge was used by repressive state machinery for attracting tourists as but one example; or how much research money within the European research tradition is still channeled towards old orientalist concerns with the translation of ancient texts, rather than more pressing contemporary issues etc.).

Secondly, I was selected as an informant to be a part of research performed "to make readers in Nepal familiar with the ways in which British researchers on Nepal are produced and operate in the UK". A long overdue reversal of the research gaze, it is part of a larger concern of the researcher's interest in how Nepal has been constituted as an object of study within area studies (in the UK, India, and the US) - he wishes to "demystify", as he phrased it to me in a recent conversation we had, the ways in which foreign academics are frequently held in Nepal - he is concerned to highlight the "conditions in which UK-based researchers on Nepal work, and their academic relationship with Nepali Society", as it was phrased in the interview.

Do you teach? If so at what level? What kinds of courses do you teach (or have taught in the past) and what Nepal related content are included in those courses? Please provide a copy of the relevant reading lists, if any?

This is how he phrased the questions specifically about teaching, although he covered a range of other subjects. My response to these questions went as follows, and also helps highlight how I went about placing Nepal material in the courses:

I have just started teaching: At UCL I taught a medical anthropology methods and classic modern ethnographies course. As a part time lecturer at Brunel for one year I taught research methods, theories around the body, and on an introductory course for medical anthropology and one on anthropology and public health. At SOAS, I am teaching a half unit on medical anthropology, and one on South Asian ethnography.

Within the medical anthropological cannon there are a number of key works that have emerged from Nepal, such as Desjarlais' Body and Emotion, Justice's Policies, Plans and People, Adams' Doctors for Democracy, and the Work of Stacey Leigh Pigg in particular. I run sessions on critical readings of these texts, in which we look at issues around the relationship to the empirical research and theory and ideas, how it is written, how much the work is theory driven etc. I am able, for these works, to apply my broader understanding of Nepal to assist the students in working through their critical readings.

I am currently developing the South Asia Ethnography course, the second half of a unit that has already dealt with some of the major theorists (Dumont, Marriott etc. etc.) within the context of an historical and political milieu. My brief was to build on this, and bring in some Himalayan material, as the other lecturer had a South India research perspective. It is how to bring Nepal into this broader south Asian context that is causing me the most anxiety. After looking at a number of reading lists of those before me, and the content of the only other Nepal focused course in the UK, the course will look at a number of issues, with particular reference to Nepal. Health related issues, ethnic

Anthropology Matters J ournal, 2003-1

http://www.anthropologymatters.com 
identity, political and communal violence, gender issues and consumption and globalisation. Three weeks will focus exclusively on Nepal - and I shall pose questions about the relationship of broader theoretical and other ideas outside of this empirical and political context - namely, ethnic identity, the rise of political violence (in comparison with Sri Lanka, Ayodhya and Mandal - with the work of Das, Daniel, amongst others) and issues around gender. Within health and consumption too, there will also be a considerable Nepal bias.

I attached a copy of the reading list as well.

I do not yet know how this material will be utilized, but it will enter into the public sphere in Nepal. On first receiving this questionnaire my immediate reaction was that this was the last thing I needed while feeling vulnerable about developing a half unit. Yet on reflection, and after looking at the suggested benchmarking for our discipline, where is the accountability for the representations, and how we teach about those from the countries we research in?

\section{After word}

As I considered how to contribute to this conference there is little doubt that I have one overwhelming, and at times all consuming sense - A rushed $\mathrm{PhD}$ completed over the summer with looming ESRC deadline, having to teach as research funds dried up, developing new lecture courses, wanting (and needing) to publish, considering how to teach and run seminars, etc. - that of being swamped, or rather stretched, like a form of paper that feels it is about to split into myriad pieces. This visceral metaphor informs my sense of self as I lurch, frequently with an overwhelming sense of under-preparedness into further positions of teaching responsibility. I feel more exhausted now than I did as junior medical doctor, a process of disciplinary retaliation well charted by Sinclair (1997). ${ }^{2}$ That many junior doctors develop both alcohol related, and mental health problems (yet deny them because of the physical training they receive), may be a lesson taken from an anthropological study of the process of "making doctors".

Finally, I note that I have also occasionally been patronized in a way that is again reminiscent of my days as a junior doctor - don't rock the boat, do your time (be a good citizen as it was once phrased to me) and you will get on. In that the competition for teaching posts is intense, with the numbers of $\mathrm{Ph}$.D graduates far outweighing the number of tenured posts, this will, I suspect, mitigate against any sense of solidarity amongst junior staff. Combine this with the shift to even longer periods in fixed term contract work prior to tenure, within a relatively small "community" where the gossip circuits, and personalized networks probably far outweighs any form of rational selection and those

\footnotetext{
${ }^{2}$ I write at a particular moment in my early academic career, just prior to a large amount of teaching at SOAS. As was highlighted by undergraduate students at a series of sessions at Brunel, questions asked about the experience of being a student at Brunel are likely to differ according to when asked. The answers received half way through fresher's week will not be the same as those elicited just prior to sitting exams. Had this conference fallen in the early summer, this paper may have been flavoured quite differently.
} 
who do not tow the party line will be recognized early. That this may entrench a particular form of tradition and hierarchy, that marginalizes the broader politics of higher education and consideration of anthropology's place, and that of more junior teaching staff within it, is regrettable.

\section{References}

Sinclair, S (1997) Making Doctors: An Institutional Apprenticeship. Oxford, New York: Berg.

Ian Harper is currently lecturing at the School of Oriental and African Studies. A qualified medical practitioner he has public and community health experience in both Nepal and India. He is currently also waiting to defend his PhD thesis, entitled "Magic, Mission and Medicalisation: An Anthropological study into Public Health in contemporary Nepal". 